\title{
Analysis of Environmental Costs' Effect in Green Mining Strategy Using a System Dynamics Approach: A Case Study
}

\author{
Amir Jafarpour (iD) ${ }^{1}$ and Siamak Khatami $\mathbb{D}^{2}$ \\ ${ }^{1}$ Department of Mining and Metallurgical Engineering, Yazd University, Yazd, Iran \\ ${ }^{2}$ Department of Computer Science, Faculty of Information Technology and Electrical Engineering, NTNU, Trondheim, Norway
}

Correspondence should be addressed to Amir Jafarpour; jafarpour.a67@gmail.com

Received 1 May 2021; Accepted 21 June 2021; Published 16 July 2021

Academic Editor: Noorbakhsh Amiri Golilarz

Copyright (c) 2021 Amir Jafarpour and Siamak Khatami. This is an open access article distributed under the Creative Commons Attribution License, which permits unrestricted use, distribution, and reproduction in any medium, provided the original work is properly cited.

\begin{abstract}
Nowadays, one of the most significant problems in mining activities is the significance of analyzing environmental issues along with mining, concentration, and mineral processing operations to achieve the goals of sustainable development. Nevertheless, mine owners refuse to include environmental costs (EC) and consider them unprofitable. Due to the ever-increasing importance of environmental and social topics in recent years, there is a vital need for assessing the EC and its impact on total mining costs and implementing green strategies by the mining managers and engineers. The current study tries to model the mining cost structure by considering the causal relationships between different factors affecting open-pit mining costs to highlight the EC's role. Furthermore, this research evaluates the effectiveness of implementing each possible mining green strategy in a large-scale copper mine using the System Dynamics (SD) approach. In this regard, seven scenarios and a combination of different environmental strategies, including mine reclamation, an environmental strategy for a condensation and processing plant, and environmental mining operations, have been considered for the SD-based economic analysis. The simultaneous use of the green mining strategies for the concentration and processing plant (Scenario 4) shows a high impact on cost reduction in the mining operation.
\end{abstract}

\section{Introduction}

Mining is one of the most important large-scale industries in developed and developing countries [1]. Sustainable development and its components, including economic, social, and environmental factors, play a major role in the decisionmaking problems of the mining projects, such as feasibility assessment, planning, and management of mining operation studies [2, 3]. Several technical and managerial studies evaluated these factors separately. The studies are conducted based on assumptions and variables with unknown values, which should be estimated using the existing data $[4,5]$. Attentions to the environment, social, and economic topics, which are the main goals of sustainable development, are of importance in mining activities [6,7]. Even with the implementation of principles and the framework of engineering, mines have a nature of being environmentally destructive in the absence of green mining construction policies [8]. Also, mines can be considered dangerous to the people who live around the mines because mining operations involve demolition. The reasons for conducting more research focusing on environmental costs (EC) in mines: (A) the environment is an undeniable part of human life; (B) human beings always need natural raw materials to survive, and (C) a balance is needed between basic needs of human beings and their destructive environmental activities.

It is necessary to evaluate the EC's role and its impact on total mining costs. In this regard, using biocompatible mining strategies entitled green mining can reduce the destructive environmental effects of mines [9]. On the other hand, paying excessive attention to environmental problems during mining operations may have an impact on increasing operating costs and reducing the overall profitability of the open-pit mine. The cost components play a significant role in the scope of changes in the economic earnings of a project, and thus their analysis is essential [10]. For this purpose, 
economic analysis on the implementation of green mining strategies in mining projects and their impacts on total costs become highly important [11]. This study considers the green mining strategies based on the concept of sustainable development and evaluates the costs resulting from the destructive environmental effects of mining and the implementation of green mining strategies, introduced in the form of sustainable strategies. The output of this study can solve the misconceptions of mining managers because they believe that the EC they spend on mining is not profitable, so mining industry managers are always avoiding the cost of the environmental solutions and even the cost of reclamation. The study also evaluates the effects of the EC of open-pit mining on total mining costs to prove that the nature of the EC is different from what mining engineers and managers have in mind.

Due to the importance of reducing the destructive effects of mining on nature and addressing the existing social problems, this study aims to find answers to the main questions using dynamic modeling: What are the advantages of considering EC in the studied problem? Does the implementation of EC technically and economically lead to achieving sustainable development goals? What is the impact of green mining strategies on sustainable development solutions? It is possible to answer these questions by considering the EC's role in reducing total mining costs and using a dynamic approach to analyze this type of cost in the mining activities. To overcome some shortcomings of static approaches, such as Multi-Criteria Decision-Making (MCDM), this study uses the SD model to reach its objectives, including modeling and formulating causal relationships and assessing the EC's role in green mining activities.

The SD approach has various advantages, including the ability to analyze complex systems, having integrated vision of all parts of the problem, evaluating the effects between the criteria affecting each other and the whole system, presenting simple and accurate analysis for complex problems, and providing an instantaneous analysis of the effects of each system component on the other components and the whole system. This study evaluates the effectiveness of each possible green mining strategy in a real-world case study by modeling the mining cost structure and considering the causal relationships between concepts. To put it precisely, the overarching aim of this study was to model the mining cost structure by considering the causal relationships between its constructive factors to highlight the EC's role using the SD model. In addition, evaluating the effectiveness of each possible mining green strategy in this sector can provide an opportunity for the managers of open-pit metal mines to choose the most appropriate and efficient scenario. Since the SD method is a dynamic analytical-mathematical method and can solve various economic problems, this approach was used in this study. The problem of economic analysis of the environmental costs of mining activities is one of the most difficult dynamic problems in mining engineering for which there is no suitable solution. Therefore, to analyze this type of cost accurately and realistically, it has been evaluated in this study.
The structure of the study is as follows. Section 2 investigates previous studies separately in the fields of environmental cost estimation of open-pit mines and SD applications in the mining sector. In Section 3, the used concepts and methods are defined. Section 4 presents descriptions of the case study and analyzes the outputs of implementation of the SD approach. Section 5 presents the conclusion and summary of the results.

\section{Literature Review}

This section discusses studies related to the EC of the mining process and researches conducted using a variety of methods on the EC of mining activities focusing on EC and total costs. Also, this section reviews applications of the SD approach, which has been widely used in solving various engineering problems and managerial-strategic decisions.

\subsection{Analysis of the Environmental Costs in Mining Activities.}

The studies about mining costs are very different and numerous. In the last decades, mining studies have been done in the field of reducing costs of operation and environmental costs of mining operations. In the following, this section reviews some researches carried out in this regard.

Elliot and Harris [12] analyzed the cost-benefit mining activities in Mozambique. This study only predicted profitcost values for the next ten years and calculated the Net Present Value (NPV) of the mine without paying attention to the relationship between the factors affecting the cash flow of the mine. In another study, Byrd and Gildestad [13] analyzed the economic and social impacts of mining activities in Afghanistan. The researchers assessed the effects of mining operations on the environment, taking into account the social components and economic parameters of mining activities. Radev [14] made theoretical studies of the economic evaluation of investment projects in the mining industry. This study focuses only on economic issues, after discussing energy and related costs in mines. Although energy is one of the most significant environmental problems in mines, this research has not investigated the destructive environmental effects of improper use of energy in mines.

Rashidinejad et al. [15] presented an environmental model to optimize the cutoff grade to minimize environmental degradation of open-pit mines (especially, acid mine drainage). This study analyzed the components' effects of sustainable development on economic problems of mineral exploitation using an operations research technique (mathematical model). However, this research investigated only those related criteria to mining cutoff grade and neglected other green mining strategies-related parameters.

Botín and Vergara [16] presented the cost management model for a sustainable economy and a permanent recovery of mining operational costs. Kusi-Sarpong et al. [17] analyzed mining industries using the green supply chain and evaluated the cost of mining operations as one of the most important parameters. This study provided green supply chain practices and developed an approach for the studied 
problem using Joint Rough Sets (JRS) and fuzzy TOPSIS. However, the fuzzy MCDM method used in this research does not provide very accurate results. Also, the proposed combined approach cannot analyze the dynamic and complex systems due to the static nature of the method. Narrei and Osanloo [18] provided the optimum cutoff grade concerning reducing adverse environmental impacts of open-pit mines. This study presented the environmental factors affecting the cutoff grade and their role in mining activities. The impact of the EC and the resulting profits on the cutoff grade-first introduced by Lane in 1988-are highlighted in this research. However, this study has not considered the dynamic nature of the studied system in grade calculation.

Xu et al. [19] studied the optimization of the production planning of open-pit metal mines, taking into account ecological costs. This study covered the EC as internal costs and within the mine optimization plan. Xu et al. [20] used the dynamic programming (DP) model to calculate the NPV of the mine for several years and for the best production scheduling. Despite using dynamic sequencing of the geologically optimum push-backs, this research has not investigated the effectiveness of the various environmental and economic factors in the proposed model. Guo et al. [21] predicted the cost of mining capital for open-pit mining projects with an artificial neural network approach. The study used Artificial Neural Network (ANN), Random Forest (RF), Support Vector Machine (SVM), and Classification and Regression Tree (CART) estimates of open-pit mining costs. Although these methods can easily estimate the desired calculations, the approaches used in this method cannot calculate the costs accurately. Brescia-Norambuena et al. [22] used stochastic modeling to calculate the cost of underground mines. This study studied productivity, production, and environmental issues. As the random model is a mathematical model, it is difficult to formulate relationships between the effective criteria and analyze the outputs in this method.

Numerous studies focused on analyzing and evaluating costs in mining industries [23-31]. However, these studies have not investigated the EC's role and its direct impact on the total costs of mining operations. In the following, some researches carried out in this regard are reviewed.

2.2. System Dynamics Applications in the Mining Sector. The SD approach can address various problems, including integrated planning and designing the strategies [32], analyzing the economic behavior [33], biological modeling [34], energy optimization [20], Bayesian approach [35], tackling environmental problems [36], and urban transport planning [37]. This, in turn, demonstrates the capability and level of trust of the SD model in the complex problem analysis. These studies show that researchers have used an SD approach to solve different engineering problems. Also, this approach has been used in the mining engineering and mining project's management analysis. The following studies are some of the most important researches focusing on SD approaches' applications in the mining sector. Cooke [38] used the SD approach in the assessment of the Westray mine disaster. This study created a general model for the mine disaster causal structure and analyzed the subsystems, including mine capacity, production, and human resources. Wang et al. [39] developed a dynamic model to plan the development of coal production and sales capacity in China. In this research, Wang et al. considered the amount of carbon dioxide emissions and demand in different scenarios and tried to identify the best plans under each scenario. Moreover, interesting research has been carried out in modeling, analyzing, and evaluating the production process and operating costs using the SD approach. Also, Lagnika et al. [40] examined the possibility of using an SD approach in analyzing mine environmental topics. Although this study aims to integrate environmental management (EM) tools based on Dynamic Simulation (DS) for mining, it has been concluded that the SD can process environmental problems.

Based on previous studies and considering the capability of the SD approach in evaluating complex systems and analyzing the relationships between the effective criteria in each system, the current study uses this approach to address the studied problem. Dynamic analysis, applying the effectiveness of different criteria, the possibility of scenariomaking based on the strategies considered by managers and experts, evaluating the effectiveness of each scenario, and the possibility of momentary analysis of the effectiveness of each criterion on the whole system are significant features of the $\mathrm{SD}$ approach. Table 1 presents a comparison between the present study and previous research with a focus on the mining sector, environmental and mining costs, as well as using the SD approach. The present study has tried to evaluate the EC's impact on total mining costs considering the causal relationships between different factors affecting open-pit mining costs that have not been done in previous studies. Besides, the role of managing the EC has been examined based on different scenarios resulting from green mining. The previous researchers have not focused on the analysis of the effectiveness of such strategies according to the EC of mining.

Considering that not much research has been done to evaluate the interaction of EC with mining costs, the output of some studies conducted with the approach of environmental cost analysis can be compared with the current research. Botín and Vergara [16] and Mchaina [41] assessed the environmental cost of open-pit mining. The comparison between these works and the current study shows that this study has results close to the real conditions of open-pit mining and the defined scenarios have the necessary efficiency in assessing the EC and their mutual impact on each other and the total costs of mining. The result of Botín and Vergara's [16] study on underground mining has only led to the presentation of a model. In this study, after presenting a list of the underground mining costs, researchers have proposed a simple model based on mathematical relationships to calculate sustainable mining costs, which is a simple model compared to the current study.

The SD model in the present study has better performance than Botín and Vergara's [16] study, due to the extent of causal relationships between the influencing factors and 
TABLE 1: Comparison of the characteristics of the current study with other studies focusing on the analysis of the environmental costs of mining.

\begin{tabular}{|c|c|c|c|c|}
\hline Researcher(s) & Year & Mining costs & Environmental costs & System dynamics \\
\hline Byrd and Gildestad & 2001 & $\checkmark$ & & \\
\hline Elliot and Harris & 2001 & $\checkmark$ & & \\
\hline Cooke & 2003 & & & $\checkmark$ \\
\hline Radev & 2003 & $\checkmark$ & $\checkmark$ & \\
\hline Rashidinejad et al. & 2008 & $\sqrt{ }$ & $\checkmark$ & \\
\hline Dehghani and Ataee-pour & 2012 & $\checkmark$ & & \\
\hline Dehghani and Ataee-pour & 2014 & $\checkmark$ & & \\
\hline Botín and Vergara & 2015 & $\checkmark$ & & \\
\hline Kusi-Sarpong et al. & 2015 & $\checkmark$ & $\checkmark$ & \\
\hline Narrei and Osanloo & 2015 & $\checkmark$ & $\checkmark$ & \\
\hline Sivakumar et al. & 2015 & & $\checkmark$ & \\
\hline de Werk et al. & 2017 & $\checkmark$ & & \\
\hline Lagnika et al. & 2017 & & & $\checkmark$ \\
\hline Akpalu and Normanyo & 2017 & $\checkmark$ & $\checkmark$ & \\
\hline Wang et al. & 2018 & $\checkmark$ & & $\checkmark$ \\
\hline $\mathrm{Xu}$ et al. & 2018 & $\checkmark$ & $\checkmark$ & \\
\hline Spitz and Trudinger & 2019 & & $\checkmark$ & \\
\hline Guo et al. & 2019 & $\checkmark$ & & \\
\hline Brescia-Norambuena et al. & 2020 & $\checkmark$ & $\checkmark$ & \\
\hline Current study & & $\checkmark$ & $\checkmark$ & $\checkmark$ \\
\hline
\end{tabular}

the system's complexity. The output of the study of KusiSarpong et al. [17] was based on a fuzzy MCDM method, namely, the fuzzy TOPSIS method, and is not comparable to the dynamic model presented in the current study. Although the TOPSIS method has found many applications, the weight of the criteria used in this method and the completion of the questionnaire (to form a decision matrix) is done based on experts' opinions. So, the probability of error in this method is higher than the SD approach. Also, the effect of factors in the mentioned method is applied asynchronously and separately in the model. The SD approach leads to more desirable outputs because the model is solved dynamically taking into account the simultaneous effect of different factors. Besides, due to the multiplicity of influential factors used in the studied problem, the proposed SD model can better model and solve this problem compared to MCDM methods. Mchaina [41] introduced only a conceptual model of environmental planning, open-pit mine reclamation, and mine closure problems. This study did not provide a comprehensive approach in comparison with the current study due to the lack of a specific mathematical model. In addition to presenting a model based on causal relationships, the present study evaluates the effectiveness of various environmental solutions in reducing the total costs of open-pit mining.

\section{Methods}

This section has investigated open-pit mining operation, minerals concentrating and processing, and the essence and nature of mining costs. Also, in the following, the theoretical principles of the SD approach are presented.

3.1. Mining Operation and Related Costs. Mining activities are one of the important sources of environmental pollution, and environmental impacts of mining on the area around mining sites can occur premining, during mining operations, or postmining $[42,43]$. An overview of open mining operations is imperative to calculate the costs of each part of the mining operation and make apparent its potential environmental degradation effects. In open-pit mining, extraction first creates a bench to perform. Mining specialists design and build up benches to a depth from the mine, and thus extraction of minerals does not have any economic losses. This method is popular in metallic mines and mass deposits [44]. In general, the mining process (from the extraction of crude minerals to the production of pure metal or mineral) in open-pit mines has the following steps:

(i) Harvesting valuable topsoil and transferring it to a suitable location

(ii) Prestripping and overburden removal

(iii) Stripping and extraction

(iv) Transferring and accumulating waste rock and ore

(v) End of mine life, mine closure, and reclamation [45] (see Figure 1)

Mining specialists must consider the mining reclamation as an integral part of the entire mine design (from the early stages of mineral extraction) due to having a high environmental impact in areas where new mines are discovered and extracted [46]. The environmental problems in mines usually include problems related to the tailings dam of the processing plant, dust caused by the activity of drilling, loading, transporting machinery, destructive effects of blasting operations (dust), contamination from the activity of processing and smelting plants, wastewater leakage from the wastewater pipeline from the plant to the tailings dam, etc. [6]. The management for the reduction of these malicious effects imposes minor costs to mining projects. In this 


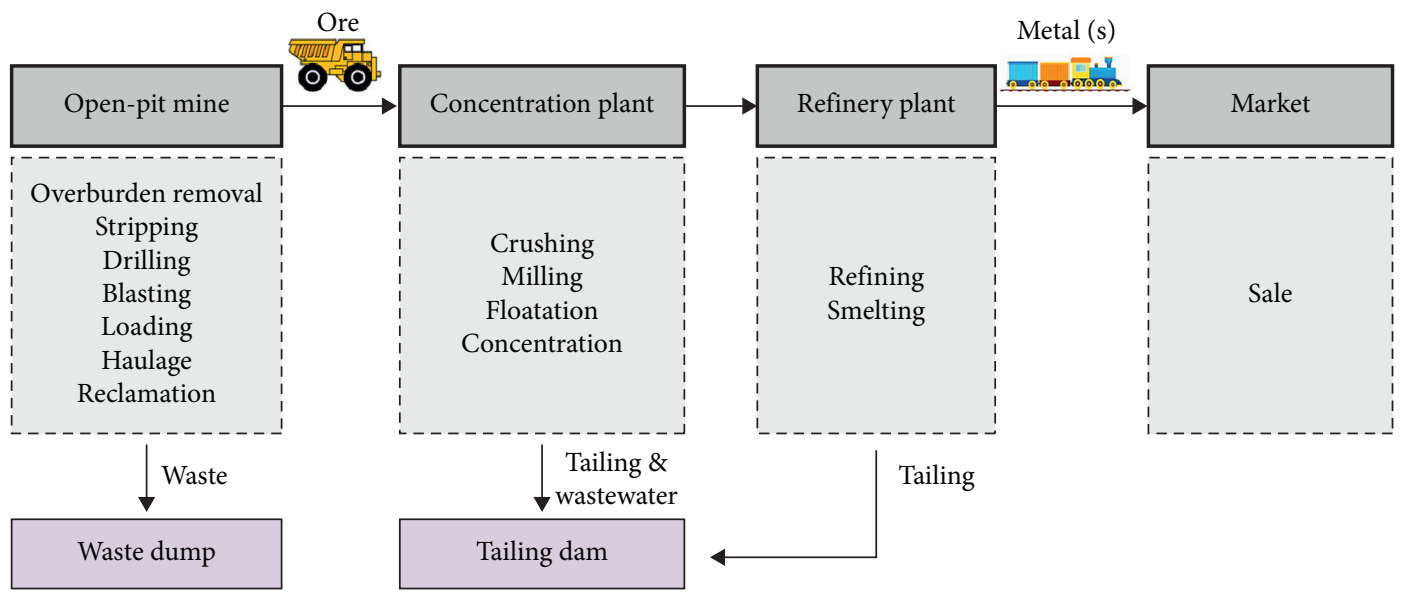

FIGURE 1: The schematic of mining operation in open-pit mines.

regard, biocompatible approaches can be considered, which are not without costs; however, the cost type of environmental strategies is different from other types of costs [47]. The cost of environmental approaches can be evaluated as positive costs because these approaches can reduce other costs, especially the cost of pollution. However, if mine owners ignore these costs, they must prepare themselves to face more costs to eliminate or control undesirable environmental consequences of mining activities. In fact, environmental fines and the EC caused by mining damages, such as destruction of pastures and forests, pollution of water/air, etc., impose great costs on mine owners. The current study aims to focus on the EC and its effect on the total costs of open-pit mining. To better illustrate the EC's role, the proposed model separated these costs from other mining costs. The mentioned costs in Figure 2 are common in the economic analysis of mining projects. On the other hand, to evaluate more accurately, environmental costs (due to the effects of pollution on the environment and related crimes) and the costs of environmental solutions (methods to reduce the effects of pollution) are considered separately.

Like all of the engineering operations, economic and financial problems are of cardinal importance in mining projects. Therefore, it is necessary to identify the nature and essence of the costs of mining projects and assess their positive/negative effects on the total costs of mining activities. There are different kinds of costs in each mining operation as well as many methods to report these costs [48, 49]. In general, mining specialists divide mining costs in open-pit mines into three classes: capital expenditure, operating costs, and general and administrative costs. In this classification, capital costs refer to the investment required for the mine and mineral processing plant. Operational costs reflect the cost of drilling, blasting, etc., performed per ton. General and administrative costs are reported annually $[44,50]$. Although the EC is considered in the above categories, the current study classifies EC in another class due to the extent of the impact of this type of cost, which separates it from other types of costs (see Figure 2). The various intrinsic and exogenous factors affect the mining cost estimation problem, and often these factors are interconnected. Accordingly, the current study focuses on causal relationships between these factors. One of the most appropriate methods to investigate problems with a cause-effect structure is the SD approach used in the present study.

3.2. System Dynamics. The SD was first introduced by Forrester in 1950, and a theory about the structure of the system and a set of tools was used to identify the structure of complex systems and analyze their dynamic behavior [51]. The SD approach can model and simulate complex economic and social systems, which can be used to make policies and strategies for change $[37,52]$. In this approach, specialists determine variables affecting the problem and their relationships firstly. Then, this approach analyzes the behavior of these variables under different scenarios with simulation. These scenarios and observed behaviors of the system will be shown visually and graphically with the least cost of the system's future experience. The SD helps managers to make more informed decisions [53]. The principles of SD and basic concepts of this method can be explained in Figure 3.

As can be seen schematically in Figure 3, the SD can be easily described by evaluating how glass is filled with water. Forrester [51] made a good point: "Filling a glass with water is not merely a matter of water flowing into the glass. Rather, there is control over the amount of water. This control is the feedback loop from the water level to the eye to hand to faucet to the water flow and back to the water level. Such closed loops control all actions everywhere." Also, Figure 3 shows a simple feedback system. In the figure, there are two symbols: a stock and a flow. The stock is a collection from different fields of accumulation or integration or level. The flow changes the amount in the stock. The flow is determined by a statement that tells how the flow is controlled by stock value compared to a target. Of course, all of the simple or complex systems include these two types of concepts: stocks and flows. Such a statement, based on the existence of two and only two kinds of variables in a system, is powerful in simplifying the decision-maker's view of the world $[51,53]$. This structure expresses the basic truth about all systems. 


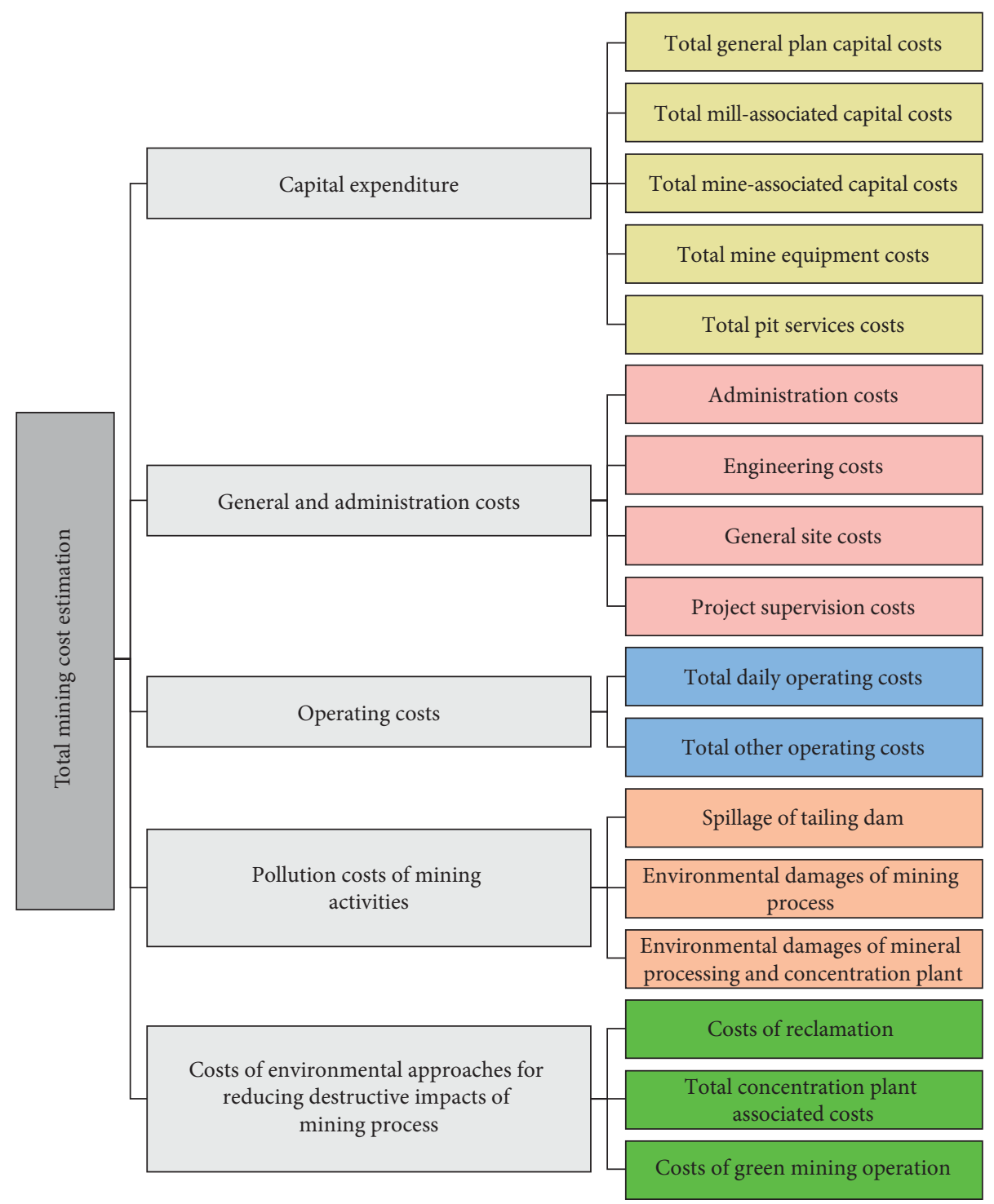

Figure 2: Types of mining extraction and mineral processing costs in open-pit mines.

Specifically, the implementation of the SD approach includes the following steps:

(i) Identification and definition of the problem: in this step, the nature of the problem, key variables affecting the problem, and horizons of interest are determined.

(ii) Determination of the system behavior based on reference patterns: in this step, the past behavior of problem variables as reference patterns is examined and their desired behaviors are determined.

(iii) Explanation of the relationship between variables and plotting of cause-effect and accumulation-flow diagrams: in this step, dynamic assumptions of the system are defined based on early assumptions that are capable of explaining the behavior of the system. Then, based on these hypotheses, key variables, reference patterns, and other data, as well as causal diagrams and accumulation and flow of the system are drawn. (iv) Development and implementation of a simulation model: in this step, based on the accumulation chart and the flow drawn in the previous step, and the assumptions expressed in the dynamic hypothesis, a simulation model is drawn for the problem. Then, initial conditions to run the simulation as well as initial values of the variables and parameters of the model are determined.

(v) Analysis of the model and designing of policies: in the last step, by implementing a simulation model and examining the model's ability under extreme conditions, the model's behavior is compared with the observed situation from past information and reference patterns to validate the model. Finally, specialists test new structures and rules to see whether desired behaviors are observed in the system by designing different policies and scenarios [54]. 

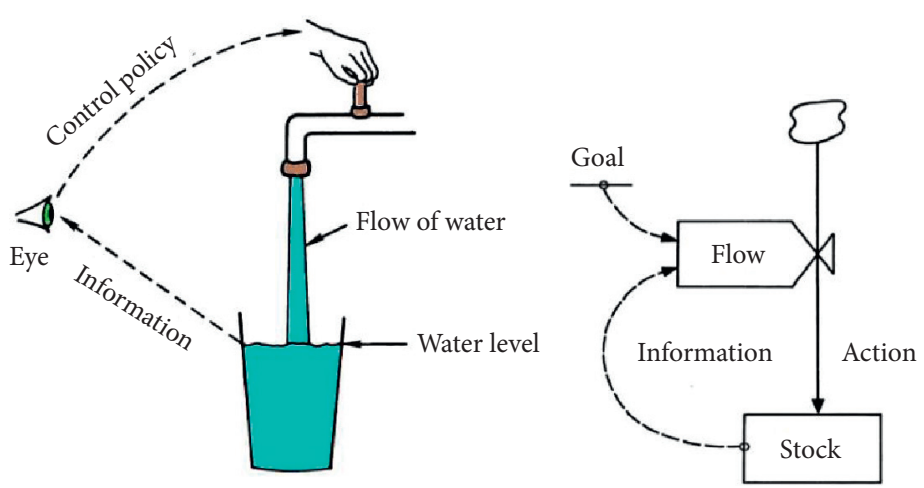

Figure 3: The simplest possible feedback system [51].

There are various software packages to model and simulate dynamic systems, but in the current study, the Vensim software has been used, which is a powerful tool for simulation, model testing, designing, and studying various scenarios in complex systems.

\section{Results and Discussion}

In this section, the open-pit mine whose information has been used in the research is introduced firstly in the case study section. Then, the second section describes the proposed SD model, and finally, the results of solving this model are analyzed.

4.1. Case Study. The present study uses the information of an active copper complex to evaluate and validate the proposed model. The Sungun copper mine is located in the northwest of Iran, adjacent to a protected area, and is registered as a living biosphere by UNESCO. This mine is active in Eastern Azerbaijan province, $110 \mathrm{~km}$ northeast of Tabriz, $75 \mathrm{~km}$ northwest of Ahar city, and $15 \mathrm{~km}$ north of Varzeqan city (see Figure 4).

The environmental significance of the region is high, which requires environmental assessment and economic analysis of environmental approaches. The deposit of this mine is porphyry copper, and its products are molybdenum and gold, which are extracted by open-pit mining. The geological resource of the deposit of Sungun copper mine is 796 million tons, and the total mineable deposit of the mine is 410 million tons. The average grade of ore (mineable deposit) is $0.6 \%$ of copper. The life of the mine is 32 years. So far, 12 years have passed since the mining activity. Thus, the remainder of the mine's life in the current study is 20 years.

The used data in the current study were collected from technical and economic documentaries of Sungun copper mine and published in technical reports about the mine. Also, the main part of data was extracted from annual statistical reports of mining industries of Iran by authors.

4.2. Model Description. At first, the current study created a model based on the relationships between effective factors to apply the SD approach. Then, a computer simulation of the studied system (i.e., environmental costs) has been performed with the implementation of the model by the software. Finally, the results have been evaluated and analyzed. The details of the implementation of this approach have been provided in the following sections.

This study used mine engineering experts' opinions, including three professors at the Urmia University of Technology and Yazd University, and seven experts from the mining engineering organization of Eastern Azerbaijan province, to determine relationships between identified factors and analyze the extent to which EC affect the total cost of open-pit mining. During a meeting, the experts determined the causal relationship between the constructive concepts of the EC, using the brainstorming technique and the Nominal Group Technique (NGT). Finally, this research has modeled a studied system based on the raw opinions of these experts. Also, this study created mathematical formulations of these linguistic relationships for use in Vensim software. Then, a graphical model has been depicted for the results, as shown in Figure 5, using the Vensim software. Graphs related to the extent of the impact of different factors have been obtained by implementing the Vensim based on the raw data. In addition to examining the basic condition (without applying effective factors related to EC), the current study defined different scenarios (see Table 2) to evaluate the impact of existing factors and their various combinations.

Regarding Table 1, this study defined the basic mode without considering the effectiveness of environmental solutions and incurring costs resulting from environmental solutions. Scenario 1 applies the costs of mine reclamation operations, including flattening of the mined land, relocation of vegetable soils, planting of trees compatible with postmining conditions, etc., in the model. In open-pit mining, these solutions are a part of the mining operation and are the last step of mining, which enters the dynamic calculations using the first scenario. Scenario 2 investigates the costs of environmental solutions related to the processing plant and concentrating the extracted ores in the dynamic model. Besides, this scenario considers the costs associated with the tailings dam. Using phytoremediation and wastewater treatment processes from the processing plant is also considered. Scenario 3 is defined based on the effect of environment-friendly mining operations costs on total open-pit mining costs. Also, in this scenario, green blasting is considered a suitable and sustainable solution for 


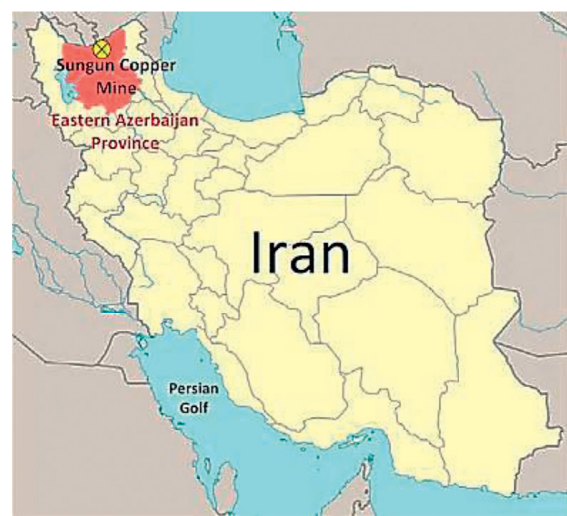

(a)

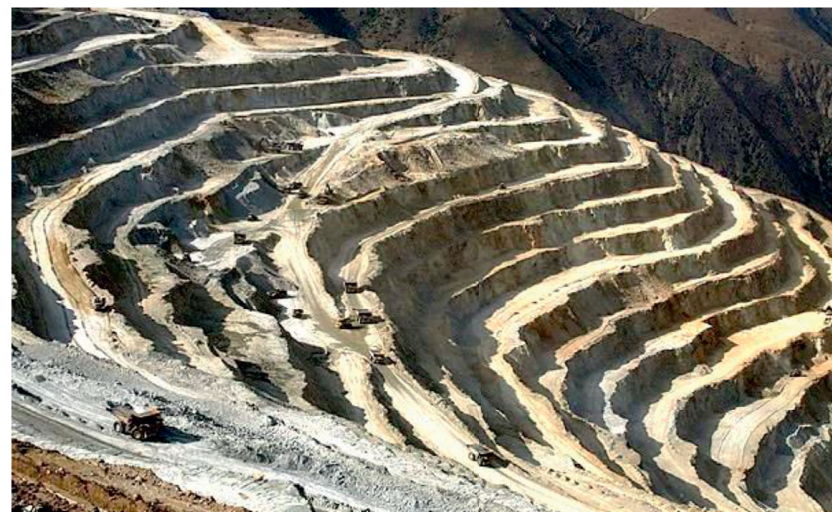

(b)

FIgURE 4: Location of the studied mine and a view of the mine [55].

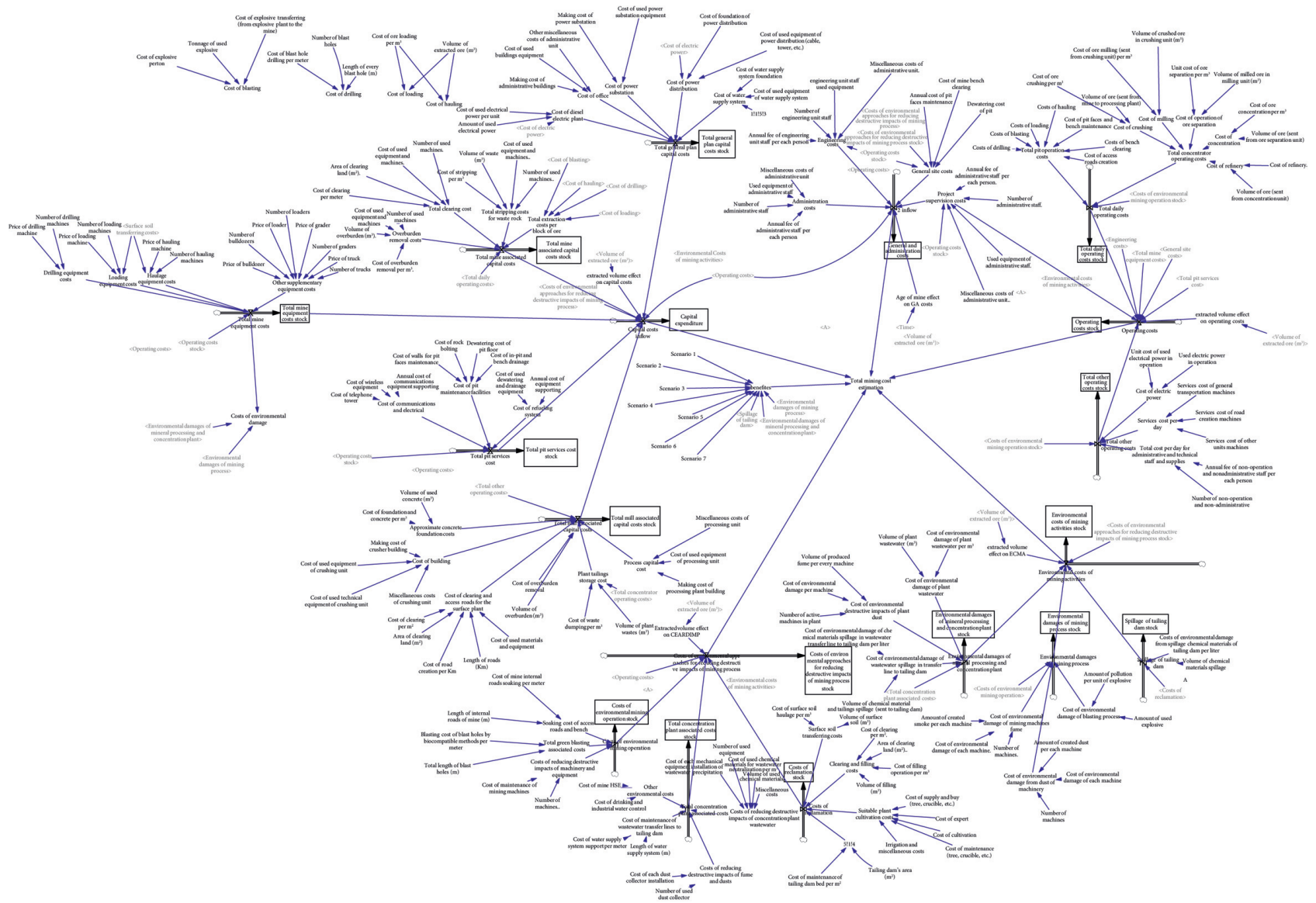

Figure 5: SD model designed in the current study.

biocompatible mining. Scenario 4 is developed based on a combination of Scenarios 1 and 2. This scenario simultaneously applies the impact of mine reclamation and environmental solutions related to the processing plant. Scenario 5 is the simultaneous application of Scenarios 1 and 3 in the SD model. Based on this scenario, costs associated with mine reclamation and biocompatible mining are applied in the model. Scenario 6 is also the simultaneous application of Scenarios 2 and 3, intending to consider the impact of the costs of environmental solutions related to the processing plant and biocompatible mining on total mining costs. Scenario 7 is another hybrid scenario, defined by simultaneous implementation of Scenarios 1, 2, and 3 in the SD model. Regarding this scenario, this study applies all costs related to environmental solutions to mining costs.

Each of the scenarios presented in the current study indicates the implementation of one or more green mining strategies to reduce the EC of the mining operation. 
TABLE 2: The introduced scenarios based on the green mining strategies.

\begin{tabular}{|c|c|}
\hline Scenario & Description \\
\hline Basic mode & Dynamic analysis without considering the impact of environmental approaches on the whole system \\
\hline Scenario 1 & Dynamic analysis by applying the costs associated with mine reclamation operations \\
\hline Scenario 2 & Dynamic analysis by applying environmental costs related to the concentration and processing plant \\
\hline & Dynamic analysis by applying the costs associated with eco-friendly mining operations \\
\hline Scenario 4 & $\begin{array}{l}\text { Dynamic analysis by simultaneously applying the costs associated with mine reclamation and the environmental approach of } \\
\text { the concentration and processing plant }\end{array}$ \\
\hline Scenario 5 & Dynamic analysis by simultaneously imposing co \\
\hline Scenario 6 & $\begin{array}{c}\text { Dynamic analysis by simultaneously applying the costs associated with the environmental approach of the concentration and } \\
\text { processing plant and eco-friendly mining operations }\end{array}$ \\
\hline Scenario 7 & $\begin{array}{l}\text { Dynamic analysis by simultaneously applying the costs associated with mine reclamation, the environmental approach of the } \\
\text { concentration and processing plant and Eco-friendly mining operations }\end{array}$ \\
\hline
\end{tabular}

According to financial resources, management can implement one or more strategies, so this study examined the impact of each strategy on the mining activities and EC (total costs) in single and hybrid forms. The output of this study shows that management can make decisions and select any of the presented scenarios. From a mining point of view, each of the proposed scenarios is one of the well-known strategies of the mining engineering department to reduce costs. In the present study, there is a basic mode that determines the current state of the system. Defining these scenarios helps decision-makers to validate the model and evaluate the effectiveness of each scenario simultaneously. In other words, the proposed model can display the impact of implementing each scenario on the basic model and validate the outputs.

All the mathematical relationships among the factors used in Figure 3 were defined based on accounting management relationships. The present study used the experts' opinions to create a significant number of relationships considered in designing the SD model. Due to the great volume of the used relationships, only some of the most important relationships are discussed in the equations (1) to (6). The used parameters in the equations have been described in Table 3.

$$
\begin{aligned}
\mathrm{TMC}= & (\mathrm{CE}+\mathrm{GA}+\mathrm{OC}+\mathrm{EC}+\mathrm{CEA})-\mathrm{UEAP}, \\
\mathrm{CE}= & (0.1 \times \mathrm{TGPC})+(0.3 \times \mathrm{TMAC}) \\
& +(0.2 \times \mathrm{TMIC})+(0.4 \times \mathrm{TME}), \\
\mathrm{GA}= & (0.25 \times \mathrm{AC})+(0.2 \times \mathrm{EC}) \\
& +(0.35 \times \mathrm{GSC})+(0.2 \times \mathrm{PSC}), \\
& \mathrm{OC}=(0.85 \times \mathrm{TDO})+(0.15 \times \mathrm{TOO}), \\
\mathrm{EC}= & (0.2 \times \mathrm{LTD})+(0.5 \times \mathrm{EDM})+(0.3 \times \mathrm{ECP}), \\
\mathrm{CEAB}= & (0.5 \times \mathrm{CR})+(0.3 \times \mathrm{TPA})+(0.2 \times \mathrm{EDC}) .
\end{aligned}
$$

These equations show the relationships between the various factors used in the SD model. In this study, because the economic issues (i.e., mining costs and environmental costs of mining activities) have been considered, the relationships between different factors of linear type have been considered.

In some relationships, the coefficient $\alpha$ has been used to investigate the impact of environmental approaches, which is the effectiveness coefficient of each one of the environmental approaches and their combination equation (7). The amount for each scenario used to implement the model is shown in Table 4.

$$
\mathrm{LTD}=(\mathrm{EDC} \times \mathrm{VCM})-(\alpha \times \mathrm{CR}),
$$

where $\alpha$ is the efficiency coefficient of the environmental approach and its value is presented in Table 4 for each scenario.

Since the purpose of the current study is to examine the total cost of mining activities, the target nodes of the SD model are total mining cost and environmental cost of mining operations. Furthermore, the main advantage of the proposed approach versus other analyzing models is the ability to define different and complex scenarios. In each scenario, the analyst may use different values in different levels for better mapping the model to the real world. Each scenario presented in the present study indicates the implementation of one or more strategies to reduce the EC of the mining operation. These strategies may be defined for potential events, harsher legislation, tax on pollution, and the related risks. The means of the "effectiveness" in the current study is the effect of each strategy that is presented individually or in the combination form of scenarios. The calculation of the effectiveness of each scenario is based on previous studies and experiences of mining and environmental experts in the real-world. For this purpose, the effectiveness of each scenario has been obtained based on the existing capability and capacity of each strategy.

4.3. Analysis of the Results. This section discusses the outputs of the proposed SD model in more detail. Figure 6 depicts the effectiveness of different scenarios using Vensim software.

Given the very large and relatively similar values of the effectiveness of some scenarios and the scale of the vertical axis of the chart (see Figure 6), the curves of the basic mode and Scenarios 1, 3, and, 5 are overlapped. In Figure 6, numerical details were not visible with good quality, and 
TABle 3: The important parameters used in the economic evaluation of environmental costs of open-pit mining.

\begin{tabular}{|c|c|}
\hline Parameter & Description \\
\hline AC & Administration costs \\
\hline AFA & Annual fee of administrative staff per person \\
\hline CE & Capital expenditure \\
\hline CEA & Costs of environmental approaches for reducing destructive impacts \\
\hline CR & Costs of reclamation \\
\hline EC & Environmental costs \\
\hline ECP & Environmental damages of concentration plant \\
\hline EDC & Cost of the environmental damage of chemical material spillage while transferring waste-water to a tailing dam per liter \\
\hline EDM & Environmental damages of the mining process \\
\hline EDMP & Environmental damages of mineral processing and concentration plant \\
\hline EGC & Engineering costs \\
\hline EMO & Costs of the environmental mining operation \\
\hline EPC & Cost of electric power \\
\hline GA & General and administration costs \\
\hline GSC & General site costs \\
\hline LTD & Leakage of tailing dam \\
\hline MAU & Miscellaneous costs of the administrative unit \\
\hline NAS & Number of administrative staff \\
\hline OC & Operating costs \\
\hline PSC & Project supervision costs \\
\hline RDI & Costs of reducing destructive impacts of machinery and equipment \\
\hline SPC & Suitable plant cultivation costs \\
\hline SPD & Service cost per day \\
\hline TCA & Total concentration plant-associated costs \\
\hline TCO & Total concentrator operating costs \\
\hline TCP & Total cost per day for administrative and technical staff and supplies \\
\hline TDO & Total daily operating costs \\
\hline TGB & Total green blasting-associated costs \\
\hline TGPC & Total general plan capital costs \\
\hline TMAC & Total mill-associated capital costs \\
\hline TMC & Total mining cost estimation \\
\hline TME & Total mine equipment costs \\
\hline TMIC & Total mine-associated capital costs \\
\hline TOO & Total other operating costs \\
\hline TPA & Total concentration plant-associated costs \\
\hline TPC & Total pit services cost \\
\hline TPO & Total pit operation costs \\
\hline UEA & Equipment used by administrative staff \\
\hline UEAP & Used environmental approach profit \\
\hline VCM & The volume of chemical material and tailing spillage \\
\hline WSR & Cost of water sprinkling at the bed of roads and benches \\
\hline$\alpha$ & Efficiency coefficient of the environmental approach \\
\hline
\end{tabular}

TABle 4: Coefficient of efficiency of different scenarios of mining based on environmental approaches.

\begin{tabular}{lc}
\hline Scenario & Coefficient of efficiency $\alpha$ \\
\hline Basic mode & 0 \\
Scenario 1 & 0.85 \\
Scenario 2 & 0.80 \\
Scenario 3 & 0.60 \\
Scenario 4 & 0.82 \\
Scenario 5 & 0.72 \\
Scenario 6 & 0.70 \\
Scenario 7 & 0.75 \\
\hline
\end{tabular}

changes were displayed in a straight line, according to the large scale of the numbers and the rounding of the numbers using Vensim software. However, in the following figures, oscillations and behaviors were visible, which were derived from the scenario of each approach individually.

Figure 6 indicates that total mining costs have been reduced significantly due to the effectiveness of scenarios related to environmental issues. Although the implementation of various environmental scenarios in open-pit mines appeared to increase mining costs, the estimation of total mining costs showed the decreased total mining costs. The reason behind this significant reduction in total mining costs is the nonimposition of environmental issues-related costs, such as fines for environmental pollution in and around the mine, changing the ecosystem of the region, destruction of natural resources, etc. If the standards are not met, owners and managers of open-pit mines should pay high environmental fines for the reclamation of the whole mining area and solving the environmental problems. 


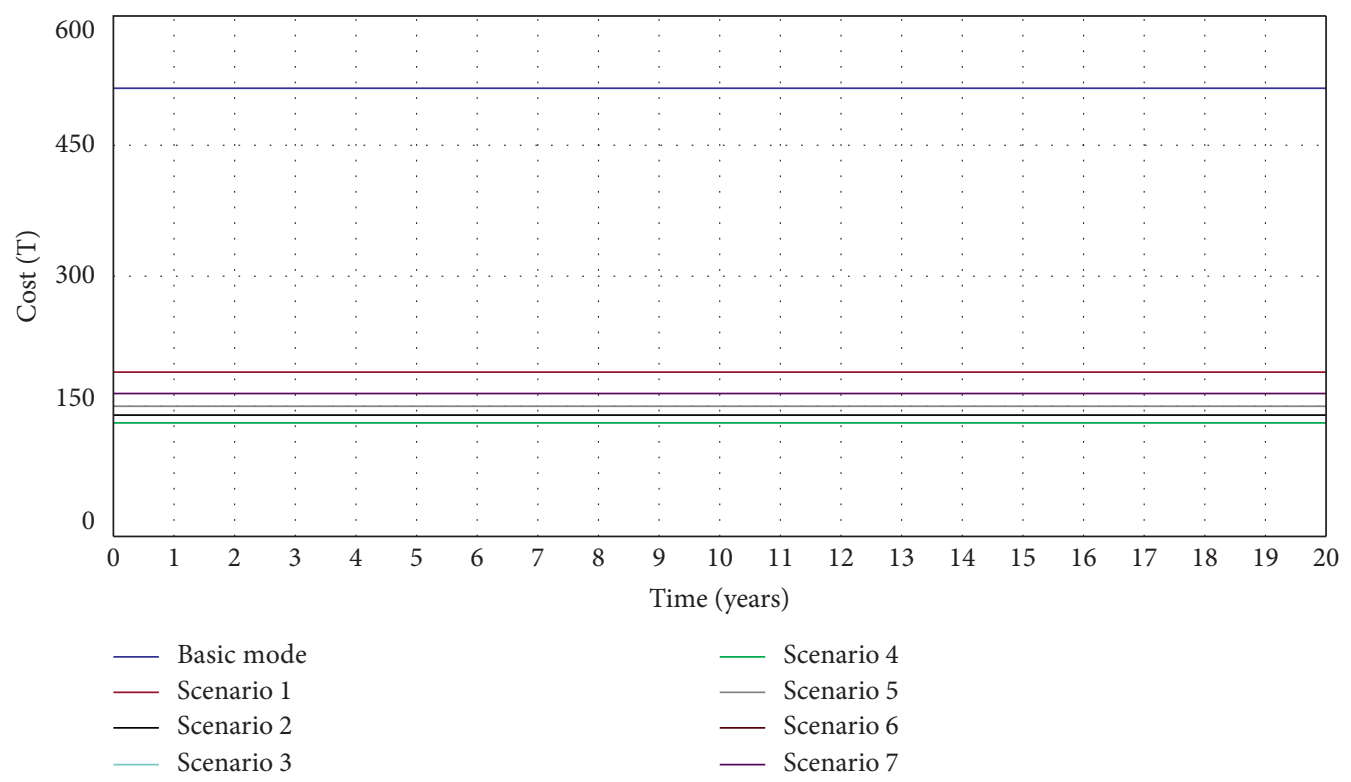

FIGURE 6: Effectiveness of different scenarios based on the output of the system dynamics model.

In some cases, failure to pay attention to environmental problems leads to mine closure by environmental protection organizations. This figure also shows that the total cost of open-pit mining operations is reduced if low costs related to the application of environmental solutions are spent. Thus, this issue is of cardinal importance for mine managers. Accordingly, the importance of the impact of costs related to environmental solutions, especially in large metal mines, on the total cost of mining is very significant.

On the other hand, implementing appropriate environmental approaches in open-pit mines can help policymakers reach sustainable development purposes. Moreover, implementing these strategies will lead to a reduction in total mining costs. Figure 6 illustrates that a significant amount of the total cost of open-pit mining has been reduced by the implementation of many approaches. Implementing Scenario 4 led to the highest reduction of costs, whereas implementing Scenario 6 had the lowest impact on the cost reduction. Small fluctuations associated with the changes resulting from the impact of various variables on the system are not visible in Figure 6. The reason is that each graph had extremely large numerical scales, and the number of fluctuations was extremely low compared to the values in each graph. Therefore, it is necessary to separately analyze the graphs of different scenarios, in which these oscillations are observed (see Figures 7 to 14).

According to the results of solving the proposed dynamic model using Vensim software, the impact of costs of environmental approaches on the estimation of total mining costs of open-pit mines and other costs of different mining processes is shown in Figure 7. Notably, rounding the outputs by Vensim software has resulted in repeating the numbers in the vertical axis of this figure. Although the general trend in the graphs of Figure 7 was ascending, the graphs had slight fluctuations, and slopes were mild. These fluctuations indicated that EC had a relatively mild growth by increasing the amount of ore extraction (and increasing the environmental damage caused by open-pit mining activities). Moreover, the rate of increase was moderate in total mining costs.

The final section of Figure 6 was relatively flat, which was about the last three years of mining activities; the sign was that total mining costs would remain constant with increasing EC. The greatest rate of decline in total mining costs can be observed in graph (e) of Figure 7, related to Scenario 4, after implementing the mine reclamation operations and the environmental approach of the concentration and processing plant (accompanied by costs). Moreover, implementing Scenario 7 (simultaneous implementation of the three environmental approaches) and Scenario 6 (simultaneous implementation of the environmental approach of the concentration and processing plant and the eco-friendly mining operation) led to the high total cost reduction. This is a significant reduction in the total cost of mining caused by environmental deterrence, which is considered in rules, standards, and environmental guidelines. It highlights the importance of mining-related environmental problems, which are considered unavoidable in open-pit mining activities. This means that by spending fewer costs on environmental solutions, the mine managers can see significant profits during the various years of mining activity.

In modeling using the SD approach, when the loop is formed, there must be a state variable to provide conditions to solve the model. Given that the Vensim software has a causal structure, the need for initial conditions was for the variables in the model to solve the model based on available values. In the current study, all the variables are dependent, and none of them had constant values. Therefore, it is necessary to define the flow of inputs to the system based on different variables and then use the delay function (delay value) to make the model solvable. This method of solving the SD models is considered a new solution approach, and one of the contributions of the present research is to solve complex problems. For example, the equation for project supervision costs is as follows: 


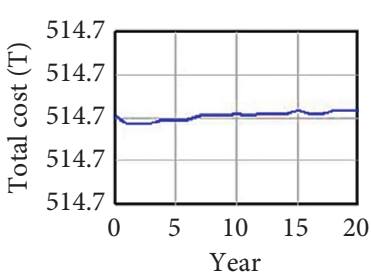

(a)

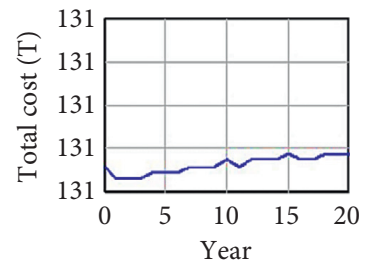

(e)

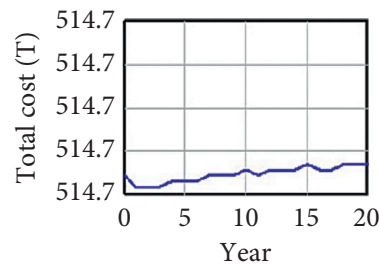

(b)

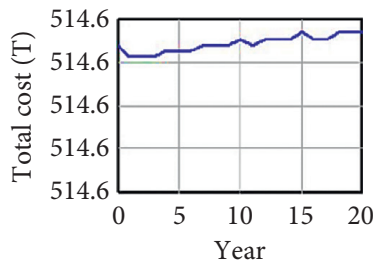

(f)

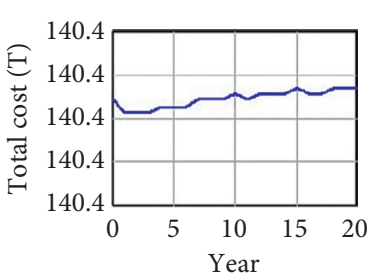

(c)

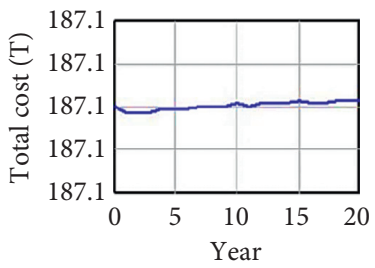

(g)

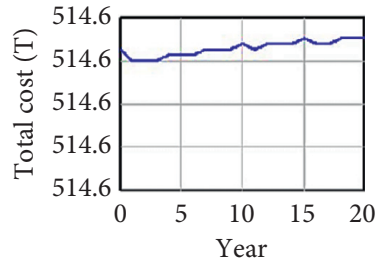

(d)

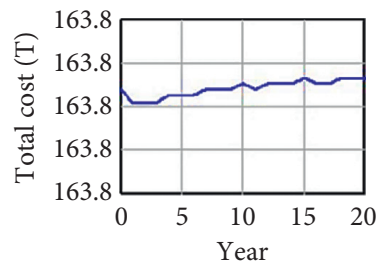

(h)

Figure 7: Estimated total costs of mining. (a) Basic mode; (b) Scenario 1; (c) Scenario 2; (d) Scenario 3; (e) Scenario 4; (f) Scenario 5; (g) Scenario 6; (h) Scenario 7.

$$
\begin{aligned}
\mathrm{PSC}= & (0.65 \times \mathrm{AFA} \times \mathrm{NAS})+(0.25 \times \mathrm{UEA}) \\
& +(0.05 \times \mathrm{MAU})+(0.05 \times \mathrm{OC}) .
\end{aligned}
$$

In the following, $(0.05 \times \mathrm{OC})$ is replaced by equation (9):

$$
(\text { OC Stock - Delay } 1(\text { OC Stock, } 1)) \times 0.05 \text {. }
$$

Moreover, the present study used binary logic to activate each of the variables to analyze the effectiveness of different scenarios. To put it precisely, the binary logic has been used to apply the individual effects of each scenario and analyze the effectiveness of each of the criteria and parameters. This means that by assigning a value of zero or one to each of the scenarios, the outputs associated with each scenario and its impact on the whole system and other components are determined. This study used the values one and zero to activate and inactivate each node or component, respectively. The cost-time graphs for the basic mode (regardless of EC) in the designed dynamic model are shown in Figure 8 by considering the initial values after implementing the model with the flow of actions related to the basic state.

Figure 8 is related to solving the model for the inflow of the variables based on Scenario 1 (the basic mode). The graphs (a), (b), (c), and (e) in Figure 8 are goal-oriented functions. In goaloriented patterns of SD models, an objective function attempts to achieve the system purpose by increasing or decreasing itself, and there is a constant trend after reaching the goal value. These functions are observed in loops, which seek to equilibrate the function and are called inventory control balancing loops. For this purpose, it is necessary to identify these loops in the model. These loops for graphs (a), (b), (c), and (d) are as follows.

According to graph (a) in Figure 8, the system had a goaloriented structure in this curve. To this end, the effect of different variables increased total mining costs to the highest level (660 million monetary units in the next ten years of mining). Then, the system was seeking another goal due to the effects of the other variables, which occurred in the final ten years of mining, and the level of costs decreased (649 million monetary units). This cost reduction continued gradually until several steps (step-by-step) due to system retargeting. Retargeting means that after the calculations for each loop and all of the stocks based on a specific goal (each scenario), the system prepares itself to perform other calculations by changing the good value of the resulting value and returning to the base state. This means that by reaching the target circuit based on the causal relationships in the system, the other system continues its calculations for each stock and each current by returning to the starting point of the calculations. This process is done permanently and dynamically while solving the model. Finally, it reached its ultimate goal (600 million monetary units) in the last ten years of mining. The effective variables in the loop related to this goal-oriented pattern are shown in Figure 9, by reviewing the designed model. The greatest impact was on the operating costs of mining, which acted as a limiting factor. Now, by assuming a review of the operating cost, the equation for this factor is as follows:

$$
\begin{aligned}
\mathrm{OC}= & (\mathrm{TME}+\mathrm{TPC}+\mathrm{TDO}+\mathrm{TOO}+\mathrm{EGC}+\mathrm{GSC}+\mathrm{PSC}) \\
& \times(1-\text { extracted volume effect on OC }) .
\end{aligned}
$$

Notably, the extracted volume effect on OC had a negative impact on the system. This structure was such that, up to the middle of the first quartile, $c$, the positive part overcame the negative sector. In other words, the extracted volume increased year by year, depending on the mine's age, until the extracted volume effect reached 1 . The same amount added to the system was removed from the system, causing the inventory or system state to remain constant.

Moreover, according to graph (b) in Figure 8, after increasing the total cost of mining, it remained constant at its final goal (400 million). The loop associated with this graph is shown in Figure 10. The operating costs in this graph were the limiting factor, which controlled the total cost of mining. However, with the assumption that the operating cost was reassessed, the equation for this factor 


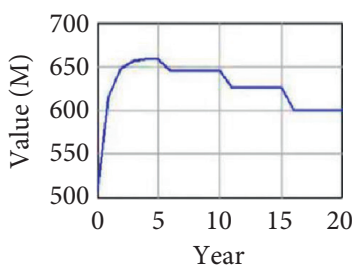

(a)

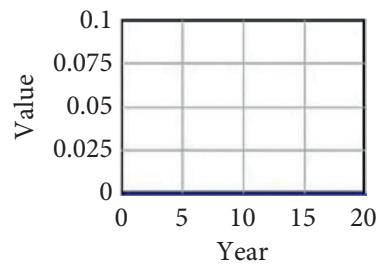

(d)

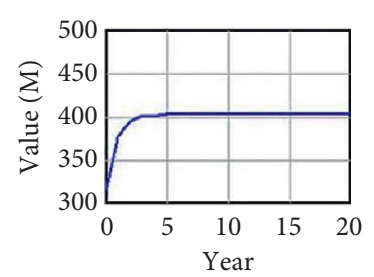

(b)

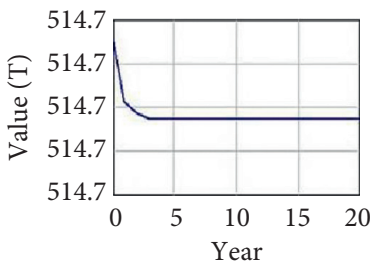

(e)

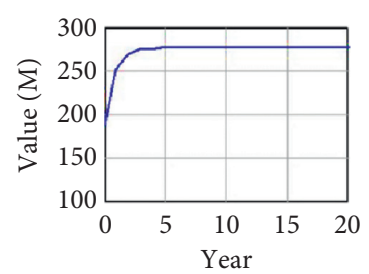

(c)

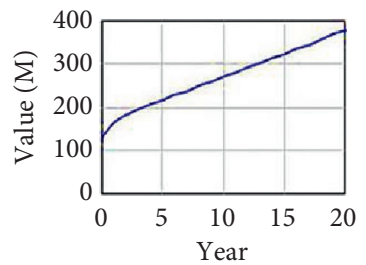

(f)

Figure 8: Dynamic model results for basic mode with apply inflow for variables. (a) General and administration costs; (b) costs of environmental approaches for reducing destructive impacts of the mining process; (c) operating costs; (d) profit; (e) environmental costs of mining activities; (f) capital costs.

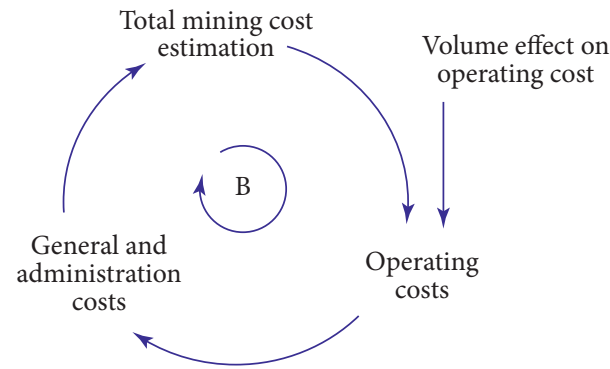

Figure 9: The loop of variables affecting graph (a) in Figure 7 (basic mode).

affected by another system was investigated using equation (11):

$$
\mathrm{OC}=(\mathrm{TPO}+\mathrm{TCO}+\mathrm{EPC}+\mathrm{SPD}+\mathrm{TCP}) \times(1-\mathrm{TDO})
$$

Total daily operating costs had a negative impact on the system. This structure was such that the positive part overcame the negative part up to the middle of the first quartile of total daily operating costs (TDO) with the year-on-year increase in mining efficiency. When TDO reached 1 , the same amount added to the system was removed from it, which caused the inventory or system situation to remain constant.

In addition, graph (c) in Figure 8 shows that if the variables related to environmental approaches were not applied (Scenario 1), the system would have a goal-oriented function, and after reaching its goal value ( 275 million), it showed a constant and steady trend. The loop associated with these conditions and the variables affecting the whole system is shown in Figure 11. The variables related to EC caused by mining activities were the limiting factor for this whole system goal situation, which was considered a negative cost. By assuming the EC examination, the equation for this factor has been investigated, as equation (12):

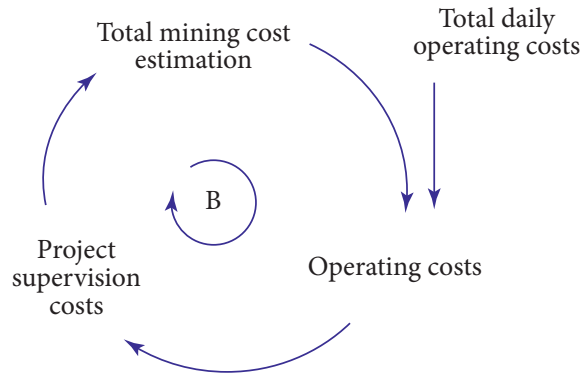

Figure 10: The loop for variables affecting graph (b) in Figure 7 (Scenario 1).

$$
\begin{aligned}
\mathrm{EC}= & (\mathrm{EDMP}+\mathrm{EDM}+\mathrm{LTD}) \\
& \times(1-\text { extracted volume effect on EC }) .
\end{aligned}
$$

It can be observed that the extracted volume effect on EC had a significant negative impact on the system. This structure was such that the positive part overcame the negative part, up to the middle of the first quartile of Figure 10. In other words, EC increased annually, and when EC reached the value of 1 , the same amount added to the system has been removed from which.

Graph (d) in Figure 8 shows that if managers have not implemented the environmental approaches (basic mode), there would be no significant profit from green mining. Notably, the profit is positive in this figure, but it is a very small amount, and the profit for each studied scenario refers to the reduction in environmental costs stemmed from applying its relevant green mining strategies/environmental solutions. In other words, in the proposed model, the profitable variables were related to EC. Therefore, if the environmental variables were not used, there would be no profit to the mine for many years.

Moreover, graph (e) in Figure 8 shows that by applying the current inflow of the environmental approaches to the system, 


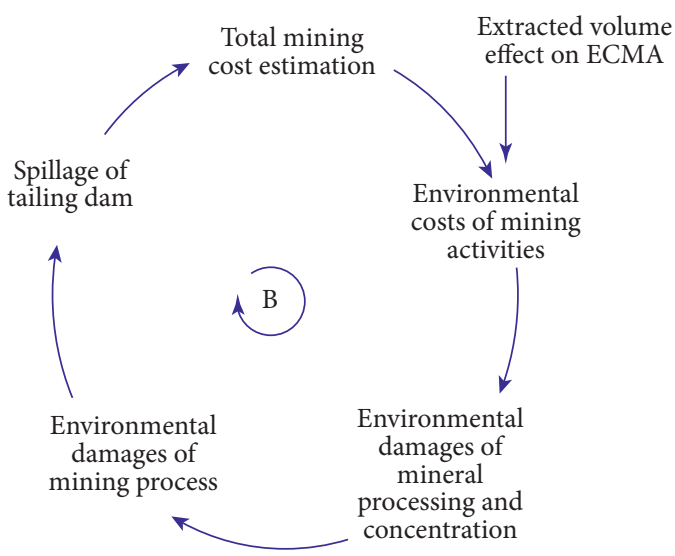

FIGURE 11: The loop associated with the variables affecting graph (c) in Figure 7 (Scenario 2).

total mining costs had a goal function and were steadily decreasing during the first six years of mining. After total mining costs reached the goal value, they showed a constant trend and remained uniform until the end of the mine's life. The equilibrium loop of this graph is shown in Figure 12. This figure illustrates that the subsets of the costs of environmental approaches were the limiting factors of the system. For analysis, by assuming CEA, the equation for this factor is as follows:

$$
\begin{aligned}
\mathrm{CEA}= & (\mathrm{EDMP}+\mathrm{EDM}+\mathrm{LTD}+\mathrm{EMO}+\mathrm{TCA}+\mathrm{SPC}+\mathrm{WSR} \\
& +\mathrm{TGB}+\mathrm{RDI})-(1 \times \text { extracted volume effect on CEA }) .
\end{aligned}
$$

Accordingly, the extracted volume effect on CEA had a significant negative impact on the system. This structure was such that the positive part overcame the negative part, up to the middle of the first quartile of Figure 11. In other words, extracted volume effect of CEA increased annually, and when this amount reached 1 , the same amount added to the system has been removed from which, causing the inventory or system state to remain constant. That means that the volume of ore extraction is directly related to the amount of pollution and environmental degradation. Also, the costs of unprincipled extraction of open-pit mines affect EC and total mining costs.

As shown in graph (f) in Figure 8, the capital inflow was not exponential, but its function was incremental and had a behavior similar to exponential functions. The start point of this graph is exponential and then has a quasilinear trend. However, the whole chart is mostly in an exponential form. Hence, it can be considered with the exponential growth pattern used in dynamic analysis. This graph had an ascending function. Accordingly, the graph showed a strong upward trend in the first few years of operation, and then it had an ascending trend, indicating that total mining costs were moderately ascending. In the final years of the mine's life, total mining costs were proven to be almost constant and had a reduced slope, indicating that its system had been recovered. The loop associated with this variable and its relation to other variables is shown in Figure 13. It showed that the underlying capital expenditure affects the whole system.

In this case, assuming that total mining costs were evaluated, the equation for this factor was investigated as equation (14).

$$
\mathrm{TMC}=(\mathrm{OC}+\mathrm{CE}+\mathrm{TGPC}+\mathrm{TME}+\mathrm{TMAC})+(0.05 \times t \times \mathrm{CE}) .
$$

Total mining costs (TMC) were observed to be ascending under the influence of several factors. Moreover, the effect of time and the almost constant increasing rate in capital expenditures, which was a small percentage, maintained its upward trend.

Given the similar situation of the cost-time graphs to implement different scenarios (with environmental costs), their dynamic analysis was the same as the one mentioned above. Moreover, by applying various currents related to the environmental variables in the proposed model, there were no changes in various graphs related to each scenario. Therefore, the analyses related to the basic mode of affairs were applied to them. In the following, only graphs with extreme changes have been analyzed (see Figure 14).

Regarding Figure 8, it can be seen that the estimated total costs of mining fluctuate in different scenarios for the studied period, and this, in turn, leads to a change in profit. But as mentioned before, the small fluctuations in Figure 14 are not visible due to the scale of the vertical axis of the diagrams. For this reason, a steady trend is observed.
Accordingly, in Figure 14, it can be seen that implementing Scenario 1 did not yield any profit, and it caused about 107 million losses, which was almost uniform throughout the years of mining. However, with implementing Scenario 2, the profit generated by this environmental approach was 375 trillion, and during the years of the mine's life, there was an almost constant trend. Moreover, the profit of implementing Scenario 3 was approximately 25 billion, the profit of implementing Scenario 4 was about 380 trillion, and implementing Scenario 5 had an equivalent value of 30 billion.

By implementing Scenario 6, the profit was about 325 trillion, and implementing Scenario 7 yielded 350 trillion profits for the mine. Notably, implementing Scenario 4 had the most profit. By comparing this result with the graphs in Figures 7 and 8, it can be seen that Scenario 4 had the largest reduction in total mining costs and also was the most profitable scenario. According to this scenario, the simultaneous implementation of the mine reclamation and the environmental approach of the concentration and processing plant in the mine significantly reduced the total costs 


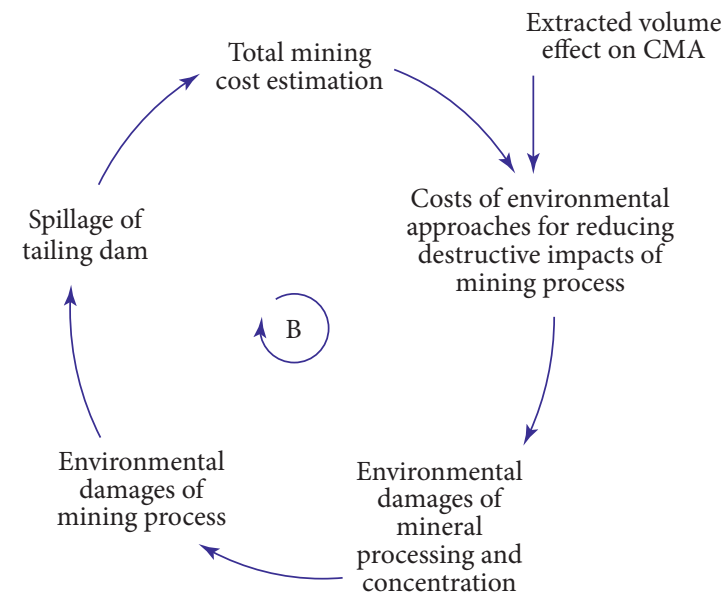

FIGURE 12: The loop associated with the variables affecting graph (e) in Figure 7 (Scenario 4).

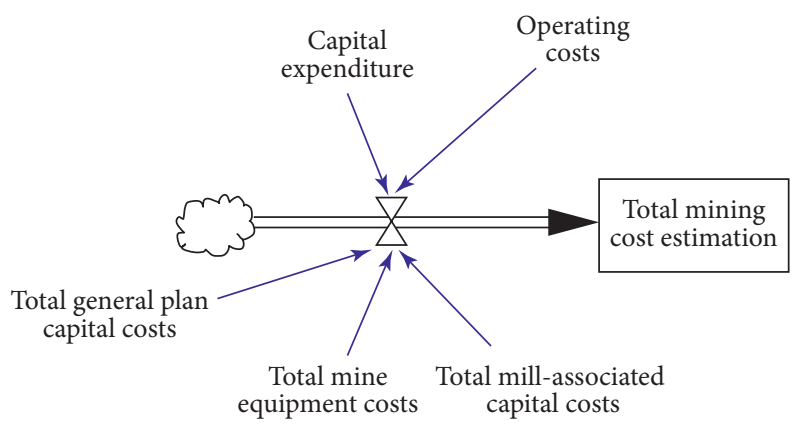

FIgURE 13: The loop associated with the variables affecting graph (f) in Figure 7 (Scenario 5).

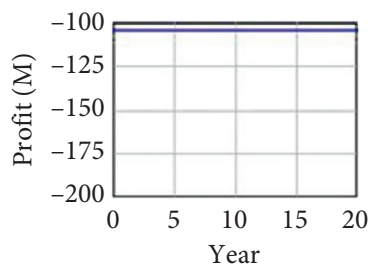

(a)

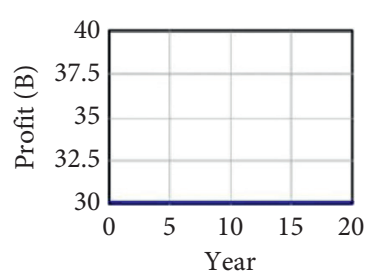

(e)

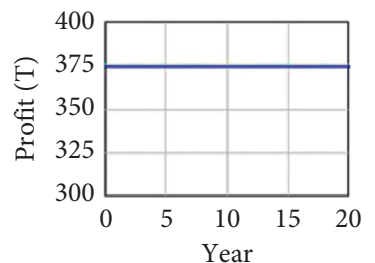

(b)

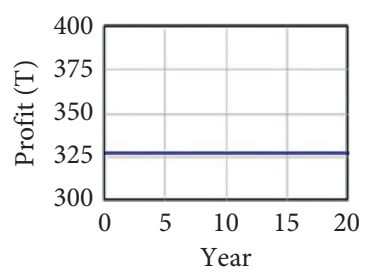

(f)

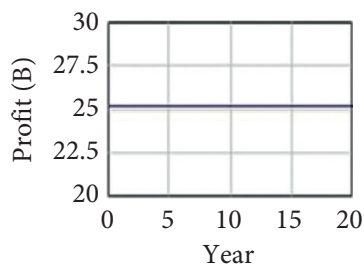

(c)

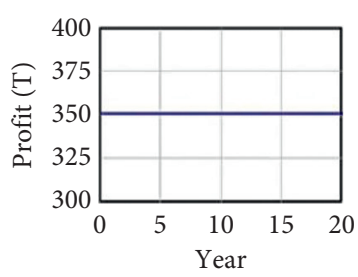

(g)

Figure 14: The results of solving the dynamic model for the profit variable from each scenario: (a) Scenario 1; (b) Scenario 2; (c) Scenario 3; (d) Scenario 4; (e) Scenario 5; (f) Scenario 6; (g) Scenario 7.

of open-pit mining. This cost reduction can also be attributed to affecting all mining and postmining activities. Regarding implementing Scenario 4 in the studied mine, in addition to the economic arguments presented in the current study, engineering calculations should be made in this regard. The implementation of Scenario 7 was also desirable and did not exclude environmental degradation related to mining activities, especially in open-pit mines, which is consistent with the goals of mining sustainable development. In addition to the positive features of Scenario 4, Scenario 7 also focuses on eco-friendly mining operations. Due to the legal requirement to implement mine reclamation strategy in open-pit mines, mentioned in Scenarios 4 and 7, at the end of their life, the potential of such mines can be used to 
develop the Geotourism industry and make a profit in the postmining period.

On the other hand, the main purpose of this study was to determine the modeling boundaries of the studied problem. To put it precisely, this study was aimed at identifying the cost components in open-pit mining operations and defining the causal relationships between these identified components according to the role of environmental costs. Providing such a system allows the decision-maker to monitor the situation by defining different scenarios and adding other economic variables such as inflation. Considering such variables outside the model's boundaries can lead to a significant positive trend in Figure 14. However, estimating such factors is challenging due to the uncertainty in the economic conditions.

In general, due to the importance of social problems in parallel with economic and environmental conditions, it is necessary to mention that by applying environmental solutions, in addition to reducing the total cost of mining operations, social issues are also somewhat resolved. Regarding social issues, if decision-makers and policymakers pay attention to environmental issues, the migration of the natives of the area and the inhabitants of the villages around the mine will decrease. Besides, due to the reduction of pollution from the mining operation and processing plants using environmental solutions, agriculture in the studied region, especially in the areas around the mine, will not be harmed. Moreover, expanding biocompatible mining activities can also increase employment in this region.

\section{Conclusion}

Given the importance of sustainability concept in managing today's industries, there is a need to evaluate its constituent components quantitatively. In this regard, the current study tried to analyze the EC's effect of green mining strategies on the total costs of mining activities using the SD approach. Therefore, due to the importance of the total cost of the mine and the EC, this study created scenarios based on green mining strategies. They proposed to emphasize the concept of sustainable development in the mining sector and related subdivisions. To assess the achievement of sustainable goals, the SD model has formulated these senarios based on the mathematical relationships between the effective parameters. The outputs of the proposed SD model indicated that Scenario 4 is the optimal scenario, compared to other defined scenarios. When Scenario 4 was implemented, the system guaranteed the highest profit, about 380 million, because of applying the largest decrease in the total costs of mining. The simultaneous use of the eco-friendly mining operations and the green mining strategy for the concentration and processing plant through Scenario 4 indicates the greatest impact on cost reduction in the mining operation. Using this approach shows the fact that by reducing the environmental damage of mining activities, not only is there no need for mining managers to pay a fine but also there is no need to spend extra funds on applying corrective measures in this regard. This profitability stemmed from considering environmental issues in mining activities that can reduce the total cost of open-pit mining projects.

\section{Data Availability}

The data that support the findings of the current study are available from the corresponding author, Amir Jafarpour, upon reasonable request.

\section{Conflicts of Interest}

The authors declare that they have no conflicts of interest..

\section{References}

[1] E. Bakhtavar, S. Yousefi, and A. Jafarpour, "Evaluation of shaft locations in underground mines: fuzzy multi-objective optimization by ratio analysis with fuzzy cognitive map weights," Journal of the Southern African Institute of Mining and Metallurgy, vol. 119, no. 10, pp. 855-864, 2019.

[2] E. T. Asr, R. Kakaie, M. Ataei, and M. R. Tavakoli Mohammadi, "A review of studies on sustainable development in mining life cycle," Journal of Cleaner Production, vol. 229, pp. 213-231, 2019.

[3] S. Ghadernejad, A. Jafarpour, and P. Ahmadi, "Application of an integrated decision-making approach based on FDAHP and PROMETHEE for selection of optimal coal seam for mechanization; A case study of the Tazareh coal mine complex, Iran," International Journal of Mining and GeoEngineering, vol. 53, no. 1, pp. 15-23, 2019.

[4] P. A. Dowd, "Risk assessment in reserve estimation and openpit planning," Transactions of the Institution of Mining and Metallurgy (Section A: Mining Industry), vol. 103, 1994.

[5] F. Pavloudakis, C. Roumpos, and M. Galetakis, "Public acceptance of surface mining projects and the determination of the marginal environmental cost," International Journal of Mining, Reclamation and Environment, vol. 26, no. 4, pp. 292-308, 2012.

[6] A. Jafarpour, J. A. Sharif, and A. Eivazi, "Reducing destructive environmental impacts of Sungun copper mine effluents with using of phytoremediation processes," International Journal of Pure \& Applied Bioscience, vol. 5, no. 2, pp. 43-55, 2017.

[7] M. M. A. Malakoutian and M. Khaksar, "SBM model based productivity evaluation," ENG Transactions, vol. 1, pp. 1-9, 2020.

[8] R. Qi, T. Liu, Q. Jia, L. Sun, and J. Liu, "Simulating the sustainable effect of green mining construction policies on coal mining industry of China," Journal of Cleaner Production, vol. 226, pp. 392-406, 2019.

[9] T. Dutta, K.-H. Kim, M. Uchimiya et al., "Global demand for rare earth resources and strategies for green mining," Environmental Research, vol. 150, pp. 182-190, 2016.

[10] M. Jahangoshai Rezaee, S. Yousefi, M. Eshkevari, M. Valipour, and M. Saberi, "Risk analysis of health, safety and environment in chemical industry integrating linguistic FMEA, fuzzy inference system and fuzzy DEA," Stochastic Environmental Research and Risk Assessment, vol. 34, no. 1, pp. 201-218, 2020.

[11] A. Warhurst and M. L. Noronha, Eds., Environmental Policy in Mining: Corporate Strategy and Planning, CRC Press, 1999.

[12] G. Elliot and G. Harris, "A cost-benefit analysis of landmine clearance in Mozambique," Development Southern Africa, vol. 18, no. 5, pp. 625-633, 2001. 
[13] W. A. Byrd and B. Gildestad, "The Socio-economic impact of mine action in Afghanistan: a cost-benefit analysis," Afghan Digital Libraries, 2001.

[14] J. Radev, "Economic analysis of investment projects in mining industry," Annual of University of Mining and Geology "St. Ivan Rilski" Humanitarian and Economic Sciences, vol. 46, no. IV, pp. 66-71, 2003.

[15] F. Rashidinejad, M. Osanloo, and B. Rezai, "An environmental oriented model for optimum cut-off grades in open pit mining projects to minimize acid mine drainage," International Journal of Environmental Science \& Technology, vol. 5, no. 2, pp. 183-194, 2008.

[16] J. A. Botín and M. A. Vergara, "A cost management model for economic sustainability and continuos improvement of mining operations," Resources Policy, vol. 46, pp. 212-218, 2015.

[17] S. Kusi-Sarpong, C. Bai, J. Sarkis, and X. Wang, "Green supply chain practices evaluation in the mining industry using a joint rough sets and fuzzy TOPSIS methodology," Resources Policy, vol. 46, pp. 86-100, 2015.

[18] S. Narrei and M. Osanloo, "Optimum cut-off grade's calculation in open pit mines with regard to reducing the undesirable environmental impacts," International Journal of Mining, Reclamation and Environment, vol. 29, no. 3, pp. 226-242, 2015.

[19] X.-c. Xu, X.-w. Gu, Q. Wang et al., "Production scheduling optimization considering ecological costs for open pit metal mines," Journal of Cleaner Production, vol. 180, pp. 210-221, 2018.

[20] Z. Xu, L. Yao, and X. Chen, "Urban water supply system optimization and planning: Bi-objective optimization and system dynamics methods," Computers \& Industrial Engineering, vol. 142, p. 106373, 2020.

[21] H. Guo, H. Nguyen, D. A. Vu, and X. N. Bui, "Forecasting mining capital cost for open-pit mining projects based on artificial neural network approach," Resources Policy, Article ID 101474, 2019.

[22] L. Brescia-Norambuena, D. Pickel, M. González, S. L. Tighe, G. Azúa, and G. Azúa, "Accelerated construction as a new approach for underground-mining pavement: productivity, cost and environmental study through stochastic modeling," Journal of Cleaner Production, vol. 251, p. 119605, 2020.

[23] K. Spitz and J. Trudinger, Mining and the Environment: From Ore to Metal, CRC Press, Boca Raton, FL, USA, 2019.

[24] R. Sivakumar, D. Kannan, and P. Murugesan, "Green vendor evaluation and selection using AHP and Taguchi loss functions in production outsourcing in mining industry," Resources Policy, vol. 46, pp. 64-75, 2015.

[25] H. Dehghani and M. Ataee-pour, "Determination of the effect of operating cost uncertainty on mining project evaluation," Resources Policy, vol. 37, no. 1, pp. 109-117, 2012.

[26] H. Dehghani, M. Ataee-pour, and A. Esfahanipour, "Evaluation of the mining projects under economic uncertainties using multidimensional binomial tree," Resources Policy, vol. 39, pp. 124-133, 2014.

[27] M. de Werk, B. Ozdemir, B. Ragoub, T. Dunbrack, and M. Kumral, "Cost analysis of material handling systems in open pit mining: case study on an iron ore prefeasibility study," The Engineering Economist, vol. 62, no. 4, pp. 369-386, 2017.

[28] E. Bakhtavar, A. Jafarpour, and S. Yousefi, "Optimal production strategy of bimetallic deposits under technical and economic uncertainties using stochastic chance-constrained programming," Journal of Mining and Environment, vol. 8, no. 3, pp. 475-485, 2017.

[29] J. Guo, H. Zheng, B. Li, and G.-Z. Fu, "Bayesian hierarchical model-based information fusion for degradation analysis considering non-competing relationship," IEEE Access, vol. 7, pp. 175222-175227, 2019.

[30] R. Mikaeil, A. Esmailzadeh, S. Aghaei et al., "Evaluating the sawability of rocks by chain-saw machines using the promethee technique," Rudarsko-geološko-naftni Zbornik, vol. 36, no. 1, 2021.

[31] S. Shojaei, A. Jafarpour, S. Shojaei, Y. Gyasi-Agyei, and J. Rodrigo-Comino, "Heavy metal uptake by plants from wastewater of different pulp concentrations and contaminated soils," Journal of Cleaner Production, vol. 296, p. 126345, 2021.

[32] F. Albrecht, O. Kleine, and E. Abele, "Planning and optimization of changeable production systems by applying an integrated system dynamic and discrete event simulation approach," Procedia CIRP, vol. 17, pp. 386-391, 2014.

[33] M. J. Radzicki, "System dynamics and its contribution to economics and economic modeling," System Dynamics, pp. 401-415, 2020.

[34] B. Hannon and M. Ruth, "Modeling dynamic biological systems," in Modeling Dynamic Biological Systems, pp. 3-28, Springer, Berlin, Germany, 2014.

[35] J. Guo, H. Zheng, B. Li, and G.-Z. Fu, "A Bayesian approach for degradation analysis with individual differences," IEEE Access, vol. 7, pp. 175033-175040, 2019.

[36] J. Liu, Y. Liu, and X. Wang, "An environmental assessment model of construction and demolition waste based on system dynamics: a case study in Guangzhou," Environmental Science and Pollution Research, vol. 27, no. 30, pp. 37237-37259, 2020.

[37] P. Norouzian-Maleki, H. Izadbakhsh, M. Saberi, O. Hussain, M. Jahangoshai Rezaee, and N. GhanbarTehrani, "An integrated approach to system dynamics and data envelopment analysis for determining efficient policies and forecasting travel demand in an urban transport system," Transportation Letters, pp. 1-17, 2020.

[38] D. L. Cooke, "A system dynamics analysis of the Westray mine disaster," System Dynamics Review, vol. 19, no. 2, pp. 139-166, 2003.

[39] D. Wang, R. Nie, R. Long, R. Shi, and Y. Zhao, "Scenario prediction of China's coal production capacity based on system dynamics model," Resources, Conservation and Recycling, vol. 129, pp. 432-442, 2018.

[40] S. B. M. Lagnika, R. Hausler, and M. Glaus, "Modeling or dynamic simulation: a tool for environmental management in mining?," Journal of Integrative Environmental Sciences, vol. 14, no. 1, pp. 19-37, 2017.

[41] D. M. Mchaina, "Environmental planning considerations for the decommissioning, closure and reclamation of a mine site," International Journal of Surface Mining, Reclamation and Environment, vol. 15, no. 3, pp. 163-176, 2001.

[42] K. A. Hudson-Edwards, H. E. Jamieson, and B. G. Lottermoser, "Mine wastes: past, present, future," Elements, vol. 7, no. 6, pp. 375-380, 2011.

[43] J. Abdollahei Sharif, A. Jafarpour, and S. Yousefi, "A hybrid fuzzy MCDM approach to determine an optimal block size in open-pit mine modeling: a case study," Journal of Mining and Environment, vol. 11, no. 2, pp. 611-627, 2020.

[44] W. A. Hustrulid, M. Kuchta, and R. K. Martin, Open Pit Mine Planning and Design, Two Volume Set \& CD-ROM Pack, CRC Press, Berlin, Germany, 2013. 
[45] H. L. Hartman, SME Mining Engineering Handbook, Society for Mining, Metallurgy, and Exploration, Inc., Littleton, CO, USA, 2nd Edition, 1992.

[46] H. Soltanmohammadi, M. Osanloo, and A. Aghajani Bazzazi, "An analytical approach with a reliable logic and a ranking policy for post-mining land-use determination," Land Use Policy, vol. 27, no. 2, pp. 364-372, 2010.

[47] F. J. Golrokh, G. Azeem, and A. Hasan, "Eco-efficiency evaluation in cement industries: DEA malmquist productivity index using optimization models," ENG Transactions, vol. 1, pp. 1-8, 2020.

[48] T. F. Torries, "Evaluating mineral projects: applications and misconceptions," Society for Mining Metallurgy and Exploartion, Denver Colorado, USA, (SME), 1998.

[49] T. Isaksson, Model for Estimation of Time and Cost Based on Risk Evaluation Applied on Tunnel Projects, Doctoral Dissertation, Byggvetenskap Royal, Institute of Technology Stockholm, Stockholm, Sweden, 2002.

[50] P. A. Dowd and C. Xu, "Financial evaluation of mining projects," in Proceedings of the APCOM XXV 1995 Conference, pp. 247-254, Brisbane, Australia, July 1995.

[51] J. W. Forrester, Some Basic Concepts in System Dynamics, Sloan School of Management, Massachusetts Institute of Technology, Cambridge, UK, 2009.

[52] N. Choucri, D. Goldsmith, S. Madnick, D. Mistree, J. B. Morrison, and M. Siegel, Using System Dynamics to Model and Better Understand State Stability, Sloan School of Management, Massachusetts Institute of Technology, Cambridge, MA, USA, 2007.

[53] J. D. Sterman, Business Dynamics: Systems Thinking and Modeling for a Complex World, McGraw-Hill, Boston Raton, FL, USA, 2000.

[54] D. M. Fisher, Modeling Dynamic Systems: Lessons for a First course, Teachers and Trainer's Guide, 2005.

[55] www.farsnews.ir. 